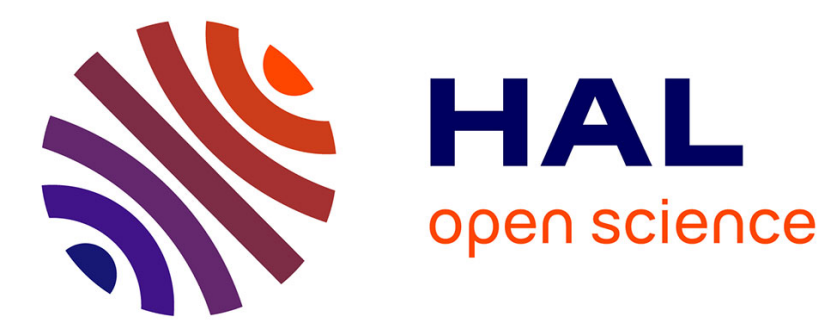

\title{
Market access and individual wages: evidence from China
}

\author{
Laura Hering, Sandra Poncet
}

\section{To cite this version:}

Laura Hering, Sandra Poncet. Market access and individual wages: evidence from China. Review of Economics and Statistics, 2010, 92 (1), pp.145-159. 10.1162/rest.2009.11418 . hal-00633785

\section{HAL Id: hal-00633785 \\ https://hal.science/hal-00633785}

Submitted on 19 Oct 2011

HAL is a multi-disciplinary open access archive for the deposit and dissemination of scientific research documents, whether they are published or not. The documents may come from teaching and research institutions in France or abroad, or from public or private research centers.
L'archive ouverte pluridisciplinaire HAL, est destinée au dépôt et à la diffusion de documents scientifiques de niveau recherche, publiés ou non, émanant des établissements d'enseignement et de recherche français ou étrangers, des laboratoires publics ou privés. 


\title{
MARKET ACCESS AND INDIVIDUAL WAGES: EVIDENCE FROM CHINA
}

\author{
Laura Hering and Sandra Poncet*
}

Abstract-We consider the effect of geography on wages using individual data from 56 Chinese cities. We present a simple new economic geography model that links wages to individual characteristics and market access. The latter is calculated as a transport cost weighted sum of surrounding locations' market capacity. After controlling for individual skills and local factor endowments, we find that a significant fraction of the interindividual differences in returns to labor can be explained by the geography of market access. We further find greater wage sensitivity to market access for highly skilled workers and for workers in private and, particularly, foreign-owned firms.

\section{Introduction}

$S^{11}$ INCE the establishment of the People's Republic of China in 1949, income inequality has been an important and sensitive political issue. However, although the country is still influenced by Maoist egalitarian ideology, unprecedented income growth over the past two decades has brought with it large and still-rising income inequality in China (Meng, Gregory, \& Wang, 2005). Coastal provinces are known for their wealth and development and inland regions for their backwardness and poverty. A coreperiphery structure of the income gradient across regions, whereby regions with low per capita income are predominantly located at the economic periphery and those with the highest income at the economic center, has long been observed in many different countries, and this same structure is also becoming apparent in China (Lin, 2005). Most analysis and policies regarding spatial inequality in China have concentrated on the gap between the eastern and western provinces. The literature on heterogeneity within these regions has focused on the contrast between rural and urban areas (Wei \& Wu, 2002). However, the ongoing growth of intraprovincial disparities has led researchers and policymakers to become increasingly interested in the origins of this new phenomenon (Ravallion \& Chen, 2007).

A number of reasons may lie behind the failure of income levels to converge. Combes, Duranton, and Gobillon (2008) note that three broad sets of explanations are frequently invoked to explain persistent spatial wage disparities: spatial differences in the skill composition of the workforce, differences in nonhuman endowments, and differences in interactions between workers or firms. While controlling for the first two factors, our paper aims to explain intranational and intraprovincial disparities through the lens of new economic geography (NEG), applied to individual data. The literature on NEG explains the emergence of a heterogeneous economic space by appealing to transport costs and

Received for publication November 5, 2006. Revision accepted for publication April 9, 2008.

* Hering: Centre d'Economie de la Sorbonne, Université Paris 1; Poncet: Paris School of Economics and CEPII.

We thank Thierry Mayer, Philippe Martin, Rodrigo Paillacar, Jean-Louis Arcand, Agnès Bénassy-Quéré, Matthieu Crozet, and two anonymous referees for their comments. increasing returns to scale (Krugman, 1991; Krugman \& Venables, 1995). One of its central tenets is the importance of proximity to consumers, as represented by the region's market access, which is typically defined as the distanceweighted sum of the market capacity of surrounding locations (Fujita, Krugman, \& Venables, 1999). The NEG "wage equation" then models nominal wages as a function of the region's market access. Wages are predicted to be higher at the economic center and lower at the periphery. Since locations closer to consumer markets enjoy lower transport costs, firms based in these locations can afford to pay higher wages and still break even.

Both theoretical developments and growing empirical evidence in the field of NEG have confirmed the impact of proximity to markets on nominal wages (Head \& Mayer, 2004; Redding \& Venables, 2003, 2004; Hanson, 2005). One prerequisite of any analysis of the determinants of regional wages is sufficient controls for individual characteristics like skill or gender, which are among the main determinants of interindividual wage heterogeneity (Mincer, 1974; Willis, 1986; Combes et al., 2008). ${ }^{1}$

Mion and Naticchioni (2005) and Combes et al. (2008) use individual data to estimate the impact of market proximity on wages, emphasizing the importance of the spatial sorting of skills in explaining wage disparities. These analyses appeal to a fairly crude measure of market access, based on Harris (1954), ${ }^{2}$ which is not directly derived from NEG theory and may, for this reason, overestimate the role of surrounding markets on local wages (Head \& Mayer, 2006).

A structural derivation of market access was first offered by Redding and Venables (2004), who estimated the impact of market access on the cross-country variation in 1996 per capita income. Head and Mayer (2006) showed that educational differences have to be taken into account in their analysis of regional wages across the EU, since not controlling for education runs the risk of incorrectly attributing wage disparities to economic geography factors. ${ }^{3}$ They propose a human capital-augmented version of the wage

\footnotetext{
${ }^{1}$ The importance of controlling for differences in worker quality is underlined in Bernard, Redding, and Schott (2005), who derive a general test of relative factor price equality across the United States that is robust to unobservable regional factor quality differences.

${ }^{2}$ See section IVA for the definition of the Harris market potential.

${ }^{3}$ Because workers with better unobservable characteristics are more likely to be located in more central areas, wage disparities across areas may be wrongly attributed to agglomeration economies. This would induce an upward bias in the estimated coefficient on market access. In addition, beside the direct effect, remoteness may hamper the accumulation of human capital, aggravating the wage disadvantage of peripheral regions (Redding \& Schott, 2003). As Breinlich (2006) argued, this will be the case if intermediate and transport cost-intensive goods use relatively more skilled labor. More central locations will then offer higher wages for skilled labor, which increases the incentives for human capital accumulation.
} 
equation, which has now become the standard approach (see Breinlich, 2006, for an application to the EU, and Lin, 2005, and Ma, 2006, with respect to China).

Other articles have applied cruder measures of market access to aggregate data to explain the impact of market proximity on income: Mion (2004) for Italy, De Bruyne (2003) for Belgium, Brakman, Garretsen, and Schramm (2004) for Germany, and Amiti and Cameron (2007) for Indonesia. Only the last two of these papers control for differences in education levels.

Most of the papers cited that include a human capital indicator do so using a measure of average education level. Although this is a substantial improvement, these indicators fail to account for the distribution of education within the labor force. Moreover, this approach does not capture other worker characteristics, such as work experience or gender, whose importance has been emphasized by labor economists (Mincer, 1974; Willis, 1986). To our knowledge, our paper is one out of only two, together with Paillacar (2006), ${ }^{4}$ combining these different strands of literature to estimate a structural model of wages with individual data. Microlevel data allow us to control for skill composition, other individual features, and firm characteristics before we investigate whether wages respond to the economic geography of their location. A further advantage of this approach is that it can alleviate the potential problem of endogeneity of market access since it is less likely that a shock to an individual wage translates into any change in local market access. ${ }^{5}$

Most of the empirical work applying NEG theory has covered developed countries. However, the agglomeration forces studied by NEG are of particular interest in developing countries. In China, due to increasing integration into the world economy, these forces are expected to have a major impact on the spatial structure of economic activity, influencing factor localization and therefore factor prices within the country. Recent empirical work on NEG in China includes Amiti and Javorcik (2008), who use firm-level data to analyze the determinants of foreign-firm entry across Chinese provinces within an NEG framework and underscore the importance of supplier and market access.

China is an especially interesting country in which to test the wage equation. According to economic theory, migration leads to factor-price equalization. In China, migration is officially restricted, and the urban labor market is strictly segmented between urban and rural workers. ${ }^{6}$ Any change in demand for local goods is therefore much more likely to lead to wage adjustment than to adjustment in the number of workers. Hence, a city facing an increase in its demand would not necessarily be able to adjust employment and

\footnotetext{
${ }^{4}$ Paillacar (2006) uses Brazilian data.

${ }^{5}$ Hanson (2005) argues that when the dependent variable is at the finest possible level, shocks in the error term will be less likely to affect the independent variable. Moreover, if the explanatory variables are aggregated to a higher level, endogeneity will again be less likely, since shocks to individual variables do not substantially affect regional variables.

${ }^{6}$ See Banister (2005) for more details on the Chinese labor market.
}

would therefore experience a rise in wages. ${ }^{7}$ Consequently, variations in market access across Chinese cities are likely to be reflected in wage differentials. Lin (2005) was the first to examine the influence of proximity to demand and supply in China. She finds, based on aggregate data, that greater proximity is associated with higher average provincial real wages. A similar analysis by Ma (2006) concentrates on the impact of market and supplier access on wages in foreigninvested firms. However, the empirical analysis of both Lin and $\mathrm{Ma}$ is limited to international markets and does not take into account local demand.

Our paper contributes to a better understanding of the relationship between market access and spatial inequality in China, as we also integrate domestic trade flows into out calculation of market access. In addition, the calculation of city-level market access allows us to analyze inequalities within provinces. Further, the use of a household survey means that we can control for individual- and firm-level characteristics, as well as alternative explanations of spatial wage disparities, such as scale economies and factor endowments. Finally, we analyze whether the impact of market access depends on worker or firm characteristics.

Our results are based on a 1995 survey conducted by the Chinese Academy of Social Sciences. Our data set covers around 6,000 Chinese workers from 56 cities in eleven provinces. We confirm that individual skills account for a large fraction of existing spatial wage disparities in China. We also find that a significant fraction of interindividual differences in wages can be explained by the geography of access to markets. After controlling for worker heterogeneity, factor endowments, and industry and provincial characteristics, our estimate of the elasticity of individual wages to market access is 0.14 . This figure lies between that of 0.1 obtained by Head and Mayer (2006) and the coefficient of around 0.3 found by Redding and Venables (2004), both estimated using aggregate data. Growing differences in trade costs or market size between Chinese cities can therefore lead to increasing wage disparities within provinces. On average, a 1 standard deviation increase in the market access of a city leads to a rise in individual wages of $29 \%$.

In the public debate, China is often presented as a country with a quasi-infinite labor supply to the manufacturing sector. If this were the case, wages in China would not respond much to international and local markets. One implication of our results is that wages in China actually respond to market access in a strikingly similar manner to that observed in industrialized countries. The Chinese labor market, from this point of view, does not seem fundamentally different.

\footnotetext{
${ }^{7}$ Although the lack of jobs in the countryside forces millions of people each year to abandon agriculture and migrate to richer parts of the country, mainly to towns, to find work in urban industries (Ping \& Pieke, 2003), their impact on urban wages might be negligible: the labor market is strictly segmented and prevents migrants from obtaining access to urban jobs or social security (Banister, 2005).
} 
We check whether the relationship between market access and wages holds for all types of workers equally or whether this relationship is valid only for certain firm types or skill profiles. We find that highly skilled workers benefit more from greater market access than do unskilled workers. These results are consistent with the NEG model, which predicts that the relationship between market access and wages will be weaker as migration is stronger. The literature on migration in China has shown that migrants in the majority have low skills.

Also, the sensitivity of wages to market access varies across firms according to their ownership type. We might expect private, recently created firms to be more flexible in terms of wages and to react more to market shocks than do state-owned firms. We find that while wages in private, and particularly in foreign, firms react strongly, wages in stateowned enterprises are largely insensitive to the city's market access.

The remainder of the paper is organized as follows. Section II outlines the theoretical framework from which the econometric specifications used in the subsequent sections are derived and presents the two key relationships that are estimated in this paper: the trade equation and the wage equation. Section III describes the data and calculates market access measures for Chinese cities. Section IV investigates the extent to which wages in China respond to these measures and carries out a number of robustness checks. Section V concludes.

\section{Theoretical Framework}

The theoretical framework underlying the empirical analysis is a reduced version of a standard NEG model of monopolistic competition based on Dixit and Stiglitz (1977), similar to that used by Fujita et al. (1999) and Redding and Venables (2004). We consider a world with $R$ locations, composed of firms operating under increasing returns to scale and producing differentiated manufactured products. Consumers' utility increases with the number of varieties. The demand for differentiated products is modeled in the usual symmetric constant elasticity of substitution way, with $\sigma(\sigma>1)$ being the elasticity of substitution between any pair of products.

The final demand for goods in location $j$ is derived from the maximization of the representative consumer's CES utility function. ${ }^{8}$ Country $j$ 's demand for a variety produced in $r$ is

$$
\operatorname{demand}_{r j}=p_{r j}^{-\sigma} \frac{E_{j}}{G_{j}^{1-\sigma}},
$$

where $E_{j}$ is location $j$ 's total expenditure on manufactured goods and $p_{r j}$ is the price of varieties from location $r$ sold in

\footnotetext{
${ }^{8}$ See Fujita et al. (1999) for a complete statement of the underlying model.
}

$j$ (consisting of the mill price $p_{r}$ and iceberg transportation costs $T_{r j}$ between the two locations: $\left.p_{r j}=p_{r} T_{r j}\right) . G_{j}$ is the aggregate price index for manufactured goods, $G_{j}$ $=\left[\sum_{r=1}^{R} n_{r} p_{r j}^{1-\sigma}\right]^{1 / 1-\sigma}$, with $n_{r}$ being the number of firms in $r$. Taking into account that $T_{r j}$ units must be shipped in order for one unit to arrive, we obtain the effective demand $x_{r j}$ faced by a firm in $r$ from location $j$ :

$$
x_{r j}=T_{r j} p_{r j}^{-\sigma} G_{j}^{\sigma-1} E_{j}=T_{r j}^{1-\sigma} p_{r}^{-\sigma} G_{j}^{\sigma-1} E_{j} .
$$

As Redding and Venables (2004) demonstrated, the price elasticity of demand is $\sigma$, and the term $G_{j}^{\sigma-1} E_{j}$ shows the position of the demand curve faced by each firm in market $j$. This latter is referred to as the market capacity of country $j$. It corresponds to local expenditure $E_{j}$ adjusted for the market-crowding effect $G_{j}$, which summarizes the number of competing firms and the prices they charge. Intuitively, a greater number of competitors, and thus a lower value of $G_{j}$, will reduce the attractiveness of $j$ for any firm exporting there. Equation (2) underscores that trade costs influence demand more when the elasticity of substitution is high. We follow the literature in referring to $\phi_{r j}=T_{r j}^{1-\sigma}$ as the "phi-ness" of trade (see Baldwin et al., 2003). This can take a value between 0 (when trade costs are prohibitive) and 1 (when trade costs are negligible). Summing over all products produced in location $r$, we obtain the trade equation (Redding \& Venables, 2004).

The total value of exports of region $r$ to region $j$ is therefore

$$
n_{r} p_{r} x_{r j}=n_{r} p_{r}^{1-\sigma} \phi_{r j} G_{j}^{\sigma-1} E_{j}
$$

As Redding and Venables (2003) emphasized, this equation for bilateral trade flows provides a basis for estimating a gravity trade model. While the last term on the right-hand side of equation (3) reflects the market capacity of region $j$, $m_{j}=G_{j}^{\sigma-1} E_{j}$, the first term, $n_{r} p_{r}^{1-\sigma}$, measures what is referred to as the supply capacity of the exporting region, $s_{r}=n_{r} p_{r}^{1-\sigma}$. This corresponds to the product of the number of varieties and their price competitiveness. ${ }^{9}$

The bilateral trade flows in equation (3), which will serve as the basis of the gravity equation estimated in section IV, can therefore be rewritten as

$$
n_{r} p_{r} x_{r j}=s_{r} \phi_{r j} m_{j}
$$

Turning to supply, we follow the standard assumptions of the Dixit-Stiglitz-Krugman model. The differentiation costs of varieties are supposed to be so small that each variety is produced by only one firm.

Increasing returns at the firm level come from the combination of a plant-specific fixed cost, $f_{r}$, and a marginal cost of production, $c_{r}$, which is region specific (Head \& Mayer,

${ }^{9}$ Redding and Venables (2003) discuss the concepts of market and supply capacity in greater depth. 
2004). The cost of producing $q_{r}$ in each region is assumed to take the form $c_{r} q_{r}+f_{r}$. Each firm maximizes gross profit. The gross profit function of region $r$ on each market $j$ is therefore $\pi_{r j}=\left(p_{r}-c_{r}\right) T_{r j} q_{r j}$. The resulting mill price for each origin $r$ is a simple markup over marginal costs:

$$
p_{r}=\frac{c_{r} \sigma}{\sigma-1}
$$

All varieties produced in a given region $r$ are thus valued at the same price (before transport costs). The gross profit earned in each market $j$ for a variety produced in region $r$ is given by $\pi_{r j}=p_{r} x_{r j} / \sigma$.

Substituting in equation (5), summing up the profits earned in each market, and subtracting the fixed costs, $f_{r}$, we obtain the net profit in each potential location $r$ :

$$
\Pi_{r}=\sum_{j} p_{r} x_{r j} / \sigma-f_{r}=\frac{1}{\sigma} c_{r}^{1-\sigma} \sum_{j}\left[\phi_{r j} G_{j}^{\sigma-1} E_{j}\right]-f_{r}
$$

Following the literature, we write

$$
\sum_{j} \phi_{r j} G_{j}^{\sigma-1} E_{j}=\sum_{j} \phi_{r j} m_{j}=M A_{r}
$$

where $M A_{r}$ is the market access of region $r$. This is simply the sum of the market capacities of all destinations $j, m_{j}$, weighted by the measure of bilateral trade costs, $\phi_{r j}$, between $r$ and $j$. This summarizes how well a location is endowed with access to markets for the goods it produces. The NEG literature highlights that firms in locations with higher market access incur lower overall transportation costs and are thus able to pay higher wages (Fujita et al., 1999). ${ }^{10}$

We follow Head and Mayer (2006) in introducing worker heterogeneity into the standard Krugman (1980) model, assuming that labor is the only production factor, and positing both a fixed, $\alpha$, and a variable, $\beta$, component of firm-level labor requirements. Apart from notation and the inclusion of individual characteristics, we obtain what $\mathrm{Fu}-$ jita et al. (1999) call the wage equation. ${ }^{11}$ This wage equation is the second key relationship that will be estimated in the next section:

\footnotetext{
${ }^{10}$ As Head and Mayer (2006) pointed out, market access bears a close resemblance to Harris's (1954) market potential. The difference lies in the fact that Harris's market potential implicitly treats $G_{r}$, the price index, as a constant and $\phi_{r j}$ is approximated by $1 /$ dist $_{r j}$. In this sense, the $M A_{r}$ is real, not nominal, since it incorporates the notion that large markets that are extremely well served by existing firms might offer considerably less potential for profits than smaller markets with fewer competitors around them.

${ }^{11}$ See Head and Mayer (2006) for details of this derivation.
}

$$
\begin{aligned}
w_{i} & =\left[\sum_{j} \phi_{r j} G_{j}^{\sigma-1} E_{j} \frac{\beta^{1-\sigma}}{\sigma \alpha}\right]^{1 / \sigma} \exp \left(\rho z_{i}\right) \\
& =\left[M A_{r} \frac{\beta^{1-\sigma}}{\sigma \alpha}\right]^{1 / \sigma} \exp \left(\rho z_{i}\right),
\end{aligned}
$$

with $z$ corresponding to worker $i$ characteristics and $\rho$ to their returns in terms of wages. ${ }^{12}$ This equation illustrates the two different ways in which a region $r$ can adjust to a shock, for example, an increase in its local demand, $E_{r}$. First, the number of firms and workers may increase, which produces a change in the price index, $G_{j}$ (quantity adjustment). In this case, the adjustment takes place inside $M A_{r}$ since $G_{r}$ compensates for the change in $E_{r}$ and total market access does not change. Alternatively, we see price adjustment, where the number of firms and workers remains unchanged and $M A_{r}$ therefore increases. Higher demand drives prices up and is compensated by an increase in wages to ensure that the zero-profit condition is maintained.

\section{The Data}

The aim of the empirical part of this paper is to see whether this wage equation applies in the context of China. We evaluate the extent to which proximity to markets can explain interindividual wage heterogeneity and growing wage disparities within Chinese provinces. In section IIIA, we describe the data sources for the explained variable, hourly wages at the individual level, as well as most of the independent variables in our model. Section IIIB details how our main variable of interest, market access, is constructed.

\section{A. Individual Data}

Our data come from the 1995 survey of the China Household Income Project (CHIP). The data set was collected by a team headed by the Institute of Economics, at the Chinese Academy of Social Sciences (Riskin, Zhao, \& Li, 2000, 2001). ${ }^{13}$ This survey covers 6,931 households and 21,694 individuals in urban China in eleven provinces. ${ }^{14} \mathrm{We}$ appeal to the theoretical model, which was developed in the framework of manufactured goods, and apply it to a variety of nonagricultural tradable good sectors (industry, transport and communication, and commerce and trade).

\footnotetext{
${ }^{12}$ In the empirical section, we will proxy $z_{i}$ with information on gender, age, education level, and years of experience at the individual level $i$. In this latter case, $\rho$ will show the percentage increase in wage from an extra year of experience.

${ }^{13}$ The Chinese Household Income Project is a joint research effort sponsored by the Institute of Economics, at the Chinese Academy of Social Sciences, the Asian Development Bank, and the Ford Foundation. Additional support was provided by the East Asian Institute, Columbia University (Riskin, Zhao, \& Li, 2000).

${ }^{14}$ The sample includes the following provinces: Beijing, Shanxi, Liaoning, Jiangsu, Anhui, Henan, Guangdong, Yunnan, Sichuan, Gansu, and Hubei (see map A1).
} 
Our empirical work covers 6,848 workers from 56 cities $^{15}$ in the eleven provinces, aged between sixteen and sixty, not declared as self-employed, for whom the basic characteristics of gender, age, work activity, years of schooling, and years of work experience are not missing, and who are not identified as outliers by the Hadi's (1994) method.

Hourly wages, $w$, are calculated using information provided directly by the survey. Our annual wage variable, expressed in yuan, is defined as the sum of the basic salary, bonuses, subsidies (housing, medical, child care, and regional subsidies), and other wages (overtime wages and wages for special circumstances). ${ }^{16}$ To obtain hourly wages, we use the information on the number of declared hours worked per week and average number of days worked per week, as well as the number of days unemployed per year. Table A2 in appendix A reports descriptive statistics of wages by province.

\section{B. Independent Variable: Market Access}

In our analysis, the key explanatory variable is market access. As shown in equation (7), for each city $c$, market access is defined as $M A_{c}=\sum_{j} \phi_{c j} G_{j}^{\sigma-1} E_{j}$. Since neither market access itself nor its components, market capacity $\left(G_{j}^{\sigma-1} E_{j}\right)$ and freeness of trade $\left(\phi_{c j}\right)$, are directly observable, we rely on the two-step procedure pioneered by Redding and Venables (2004). In this approach, the market capacities, $m$, of international and national trading partners, as well as transport costs, $\phi$, can be estimated using a gravity equation.

Taking natural logarithms in equation (4) yields the basic econometric specification used for the trade equation, so the total value of exports to region $j$ from all firms based in region $r$ is given by

$$
\begin{aligned}
\ln \left(X_{r j}\right. & \left.=n_{r} p_{r} x_{i j}\right)=\ln s_{r}+\ln \phi_{r j}+\ln m_{j} \\
& =F X_{r}+\ln \phi_{r j}+F M_{j} .
\end{aligned}
$$

The empirical estimation of equation (9) provides us with estimates of the two components of market access: freeness of trade and market capacity. Importer fixed effects correspond to the log of the unobserved market capacity of the importer region $j, F M_{j}=\ln m_{j}=\ln \left(G_{j}^{\sigma-1} E_{j}\right)$, while exporter fixed effects $\left(F X_{r}\right)$ capture the log of the exporter's supply capacity, $s_{r}$. We next estimate the gravity equation and then use the parameter estimates from this regression to calculate market access for each Chinese city.

Estimation of the Trade Equation. For the estimation of the trade equation, we rely on a number of different data

\footnotetext{
${ }^{15}$ See table A1 for the complete list of cities.

16 To address the concern that our empirical results in section IV may be driven by differences in the sources of compensation, we run estimations with different wage definitions. The results, available on the S.P.'s Web site (http://team.univ-paris1.fr/teamperso/sponcet/), do not change according to the inclusion of exclusion of subsidies and other income from the work unit.
}

sources to construct our bilateral trade flows data set covering intraprovincial, interprovincial, international, and intranational trade flows. ${ }^{17}$

Since the most disaggregated level of bilateral trade data is at the provincial level, we first estimate the trade equation on the international and domestic trade flows of Chinese provinces and international countries to predict their respective market capacities.

All trade flows are merged into a bilateral trade flows data set covering 29 Chinese provinces and around 200 countries of the rest of the world (ROW). The estimate of equation (9) based on this complete data set allows us to compute the market capacities of Chinese provinces and foreign countries based on their exports to all destinations (domestic and international). Following previous work on border effects in Chinese provinces, we allow for impediments to domestic trade to be different from impediments to international trade (Poncet, 2003). ${ }^{18}$ Transport costs, $\phi$, in our gravity equation are therefore assumed to depend on bilateral distances, and a series of dummy variables indicating what type of border is crossed.

Allowing border effects to vary according to trading partners, equation (9) yields the following trade regression, where B denotes dummies:

$$
\begin{aligned}
\ln X_{r j}= & F X_{r}+F M_{j}+\delta \ln \text { dist }_{r j}+\varphi B_{r j, r \text { or } j \in \text { China }}^{\text {foreign }} \\
& +\varphi^{*} B_{r j, r \& j \in R O W}^{\text {foreign }}+\psi \text { contig }_{r j} \\
& +\vartheta B_{r j, r \neq j, r \& j \in \text { China }}^{\text {provincial }} \\
& +\xi B_{r j, r=j \in R O W}^{\text {intranational }}+\varsigma_{r j} .
\end{aligned}
$$

This equation demonstrates the different types of transport costs according to whether trade occurs between a Chinese province and foreign countries $\left(\delta \ln \operatorname{dist}_{r j}+\varphi+\psi\right.$ Con$\left.t i g_{r j}\right)$, between two foreign countries $\left(\delta \ln d i s t_{r j}+\varphi^{*}+\right.$ $\psi$ Contig $_{r j}$ ), between a Chinese province and the rest of China $\left(\delta \ln\right.$ dist $\left._{r j}+\vartheta\right)$, within foreign countries $(\delta \ln$ $\left.d_{i s t_{r j}}+\xi\right)$, or within Chinese provinces $\left(\delta \ln d i s t_{r j}\right) .{ }^{19} \mathrm{In}$ these last two cases, only internal distance affects the freeness of trade. The accessibility of a Chinese province or a foreign country to itself is modeled as the average distance between producers and consumers in a stylized representation of regional geography, which gives $\phi_{r r}=d i s t_{r r}^{\delta}=$ $(2 / 3 \sqrt{\text { area } / \pi})^{\delta}$, where $\delta$ is the estimate on distance in the trade equation.

\footnotetext{
${ }^{17}$ See appendix B for details of the data sources for the trade flows and production indicators for Chinese provinces and international countries used to estimate the trade equation.

${ }^{18}$ This article finds domestic and international border effects of Chinese provinces to be around $27=[\exp (3.30)]$ and $400=[\exp (6)]$, respectively, in 1997. The figure of 27 means that individuals in a given province consume 27 times more local products than products from other Chinese provinces. See Poncet $(2003,2005)$ for more on the existence, level, and evolution of impediments to interprovincial trade flows in China.

${ }^{19}$ Where dist $_{r j}$ denotes the great circle distance between $r$ and $j$.
} 
Being neighbors dampens the border effect contig $_{r j}=1$ for pairs of partners that are contiguous).

Equation (10) is estimated for $1997,{ }^{20}$ yielding countryor region-specific estimates to construct Chinese provinces' market access. The results are shown in table A3. ${ }^{21}$ Our estimated distance coefficient is similar to those found in the related literature, as is the impact of contiguity. We confirm the finding in Poncet (2003) that the border effect inside China is important. We furthermore find impediments to trade to be greater between China and the rest of the world than between countries included in our sample (which are mostly members of the WTO and are therefore much more integrated in the world economy in the 1990s than was China). Map A1 in appendix A shows the distribution of the estimated provincial market capacities.

Calculating Market Access. The data set on wages gives the location of each individual by reporting his or her province and city of registration. ${ }^{22}$ To compute the market access of cities, we apply Head and Mayer's (2006) allocation rule. Following this rule, the estimated market capacity $m_{j}=G_{j}^{\sigma-1} E_{j}$ of province $j$ is allocated to subunits (cities) $c$ according to their shares in province $j$ 's economic activity. This allocation rule relies on two hypotheses. The first is the assumption of homotheticity, so that the expenditure of city $c$ is given by $E_{c}=\left(y_{c} / y_{j}\right) E_{j}$, where $y_{c} / y_{j}$ is city $c$ 's share of provincial GDP. The second is that $G_{j}$, the supply index, is approximately constant within provinces $-G_{c}=G_{j}$, for all cities inside $j$. The combination of these assumptions yields the market capacity of each city $m_{c}=\left(y_{c} / y_{j}\right) m_{j}$.

The province-level market capacity $\left(m_{j}=G_{j}^{\sigma-1} E_{j}=\right.$ $\left.\exp \left(F M_{j}\right)\right)$ is then allocated to cities inside province $j$ according to the GDP share ${ }^{23}$ of each constituent city $c$ :

$$
\begin{aligned}
m_{c} & =G_{c}^{\sigma-1} E_{c}=y_{c} / y_{j} m_{j}=y_{c} / y_{j} G_{j}^{\sigma-1} E_{j} \\
& =y_{c} / y_{j} \exp \left(F M_{j}\right) .
\end{aligned}
$$

Note that while the lack of subprovincial trade data forces us to choose an allocation rule for provincial competition-

\footnotetext{
${ }^{20}$ As explained in appendix B, the data on interprovincial trade flows are limited to 1997. For consistency, we decided to rely on trade flows for a single year, 1997, to calculate the estimates used to compute provincial market access. Section IV will regress individual wages for 1995 on market access for 1997. We argue that the associated time discrepancy should not be a problem because of the relative persistence over time of market access. The potential problem of reverse causation between wages in 1995 and market access in 1997 will be addressed in section IV.

${ }^{21}$ Importer and exporter fixed effects are included in the regression, so that the border effect within foreign countries $\left(\delta \ln d i s t_{r j}+\xi\right)$ is captured by their fixed effects. The reference category in the regression is withinChina provincial trade.

${ }^{22}$ The entire country is divided into 27 provinces plus four "supercities" with province status: Beijing, Chongqing, Shanghai, and Tianjin. The urban population is further divided into prefecture-level and county-level cities. Our data set consists of information on individuals in prefecturelevel cities or county cities.

${ }^{23}$ The GDP shares are obtained from the China's State Statistical Bureau.
}

weighted expenditure $m$, the other component of market access, $\phi$, uses genuine city-level information. ${ }^{24}$

Finally, we can compute each city's market access, which consists of four components, corresponding to the four sums in equation (12): local market access, provincial market access (from all other cities $k$ in the same province), national market access (from all other Chinese provinces), and rest of the world (ROW) market access.

Formally, the market access of city $c$ to all regions and countries $j$ (including itself) is given by:

$$
\begin{aligned}
M A_{c}= & \phi_{c c} G_{c}^{\sigma-1} E_{c}+\sum_{k \in \text { province }} \phi_{c k} \frac{y_{k}}{\sum y_{k}} G_{j}^{\sigma-1} E_{j} \\
& +\sum_{j \in \text { China }} \phi_{c j} G_{j}^{\sigma-1} E_{j}+\sum_{j \in R O W} \phi_{c j} G_{j}^{\sigma-1} E_{j} \\
= & \operatorname{dist}_{c c}^{\delta}\left(y_{c} / y_{j}\right) \exp \left(F M_{j}\right) \\
& +\sum_{k \in \text { province }} \operatorname{dist}_{c k}^{\delta} \frac{y_{k}}{\sum y_{k}} \exp \left(F M_{j}\right) \\
& +\sum_{j \in \text { China }} \operatorname{dist}_{c j}^{\delta} \exp (\vartheta) \exp \left(F M_{j}\right) \\
& +\sum_{j \in \text { ROW }} \operatorname{dist}_{c j}^{\delta} \exp \left(\varphi+\psi \text { Contig }_{r j}\right) \exp \left(F M_{j}\right)
\end{aligned}
$$

where $F M_{j}$ and the parameters $\delta, \vartheta, \varphi$, and $\psi$ are estimated in the trade equation.

\section{Empirical Results for the Wage Equation}

\section{A. Wage Equation-Baseline Specification}

Having calculated market access at the city level, $M A_{c}$, we can now run the regressions of our human-capital augmented version of the wage equation. Table A4 shows the summary statistics of all variables used in this section.

Taking the natural logarithm of equation (8) and denoting individuals by $i$ and cities by $c$, the econometric baseline specification becomes

$$
\ln w_{i c}=a+b \ln M A_{c}+\rho z_{i c}+\varepsilon_{i c},
$$

where $a=-(1 / \sigma) \ln \left[\alpha \sigma \beta^{\sigma-1}\right]$ and $b=1 / \sigma$.

As discussed by Head and Mayer (2006), the intercept, $a$, depends on the input requirement coefficients $\alpha$ and $\beta$. These are likely to vary across sectors, in part because of variations in capital intensity. As such, we estimate equation (13) with industry and later also industry-province specific constants. Our benchmark estimates are obtained by OLS.

\footnotetext{
${ }^{24}$ In section IV, we will check that our results do not significantly change according to the choice of the indicator (GDP, population or living expenses) used to apportion provincial market capacity and that they also hold after controlling for local price differences directly in the regression.
} 
Out of the 6,848 individuals in our sample, 769 do not report current wages or working hours..$^{25}$ To ensure that our wage results are not affected by selection bias, we use a Heckman procedure to see whether the probability of reporting nonzero wages is exogenous (Heckman, 1976). ${ }^{26}$ The results do not reject the absence of selection bias, so we resort to OLS.

The structure of our data raises the problem of clustering of errors. We suspect that the observable and unobservable characteristics of the various wage earners within the same location and industry may be correlated. Moulton (1986, 1990) emphasizes that the typical OLS measures of variance could understate errors by a potentially large factor, leading to poor inference. In this paper, we correct for the correlation of errors between individuals within a specific province and industry, using Rogers's (1993) correction.

A final econometric problem arises from the two-step calculation of market access. This variable is calculated from parameters that are themselves estimated with standard errors in an initial regression. We correct for biased standard errors by applying the bootstrap procedure to each of our regressions.

Our estimated specification can be thought of as a Mincer equation augmented to include NEG market access. It is thus worth checking that our results on the basic determinants of wages (years of school, age, work experience, gender, and Communist Party membership), are consistent with the correlations found in the existing literature.

The first column of table 1 reports the results of a wage regression using these variables and industry dummies. All of the variables have a significant impact on wages, explaining $15 \%$ of the difference in wages between individuals. This specification corresponds to Mincerian (hourly) earnings functions (Mincer, 1974). Our results are consistent with the vast labor economics literature applied to China. Specifically, our estimates confirm the very low wage returns to education in China. Our estimated rate of return to education is $3.4 \%$, which falls in the $2 \%$ to $5 \%$ range obtained by Chen, Démurger, and Fournier (2005) and Zhao

\footnotetext{
${ }^{25}$ In the original sample, 8,523 individuals work in the three nonagricultural tradable sectors we consider. Of these, the exact location of 909 individuals is unknown, and 191 have missing data on schooling or work experience. We further limit our sample to individuals aged between sixteen and sixty, thereby excluding 465 additional observations. In addition, we exclude 80 individuals who say that they are self-employed (in single-person enterprises), since profits and wages cannot be properly distinguished in this case. Finally, to ensure that our estimation results are not driven by outliers, we rely on Hadi's (1994) method in all regressions to identify multiple outliers; this procedure excludes thirty observations in the wage data. Of the 6,848 remaining individuals, 769 do not provide information on wages or working hours or declare zero wages.

${ }^{26}$ This selection issue actually covers two separate phenomena: those who are currently working but do not provide a figure for wages and those who report a sector and work experience but are not currently working. We appeal to five variables (a dummy "married" interacted with gender, nonlabor income, household wealth, and size) that we imagine affect the probability of reporting a wage figure but have no impact on the actual level of wages. For space reasons, we do not report the results here, but they are available on S.P.'s Web site.
}

(2002), among others. These estimated returns are considerably lower than both the $10.1 \%$ world average and the $9.6 \%$ Asian average, as well as the $11.2 \%$ to $11.7 \%$ range for low- and middle-income countries (Psacharopoulos, 1994). Our empirical results on gender-wage differentials (to the detriment of women) and on returns to experience also correspond to those found in the literature (Chen, Démurger, \& Fournier, 2007). We furthermore confirm the significant impact of belonging to the Communist Party ( $\mathrm{Li}, 2003$ ). Communist Party membership raises wages by about $9 \%$.

Adding market access as an independent variable in column 2 leads to an increase of 7 percentage points in the $R^{2}$, so that market access contributes significantly to the explanation of wage differentials. The estimated coefficients on the other variables remain similar to those in the first column.

Our aim is to determine whether these results also apply to cities within the same province. ${ }^{27}$ Therefore, the regressions from column 3 in table 1 on are all performed with province-industry fixed effects. We also control for the clustering of error terms at this level. China being a country with significant differences between provinces in terms of policies, endowments, and development, the provinceindustry fixed effects will take into account this heterogeneity and purge the market access impact of any specific effects of provinces or industries on individual wages.

We find that even after introducing province-industry fixed effects, market access remains statistically significant at the $1 \%$ level and has a coefficient of around 0.14 . On average, a 1 standard deviation increase in the market access of a city would lead to an average increase in individual wages of $29 \%$.

In columns 4 and 5 of table 1, we introduce fixed effects to control for firm ownership ${ }^{28}$ and workers' occupational category. ${ }^{29}$ The coefficients on the dummies for firm ownership in column 4 reproduce the results found in earlier work, in particular, Chen et al. (2005), who use the same data set as we do. Chen et al. show that both foreigninvested firms (including both foreign- and Sino-foreign owned enterprises) and state-owned firms (SOEs) pay higher wages than do firms with other owners, ${ }^{30}$ while SOEs provide the highest levels of bonuses and subsidies. ${ }^{31}$

\footnotetext{
${ }^{27} \mathrm{Up}$ to this stage, no province dummies have been introduced, so that the estimations focus on differences among the 56 cities, whatever their province of location.

${ }^{28}$ Ownership types cover state-owned enterprises at the central or provincial level (central SOEs), local publicly owned enterprises (local SOEs), urban collective enterprises, private enterprises, foreign-invested enterprises, Sino-foreign joint ventures, and others.

${ }^{29}$ The categories here are owner of private or individual enterprise, owner and manager of private enterprise, professional or technical worker, head of institution, division head in institution, office worker, skilled worker, unskilled worker, and others.

${ }^{30}$ The omitted category in columns 4 and 5 is private firms.

${ }^{31}$ Zhao (2002) highlights the higher nonwage benefits provided by SOEs (e.g., pensions, housing, and health care) as a key explanation for the immobility across different ownership enterprises in China.
} 
TAble 1.-Benchmark Wage Equation Estimations

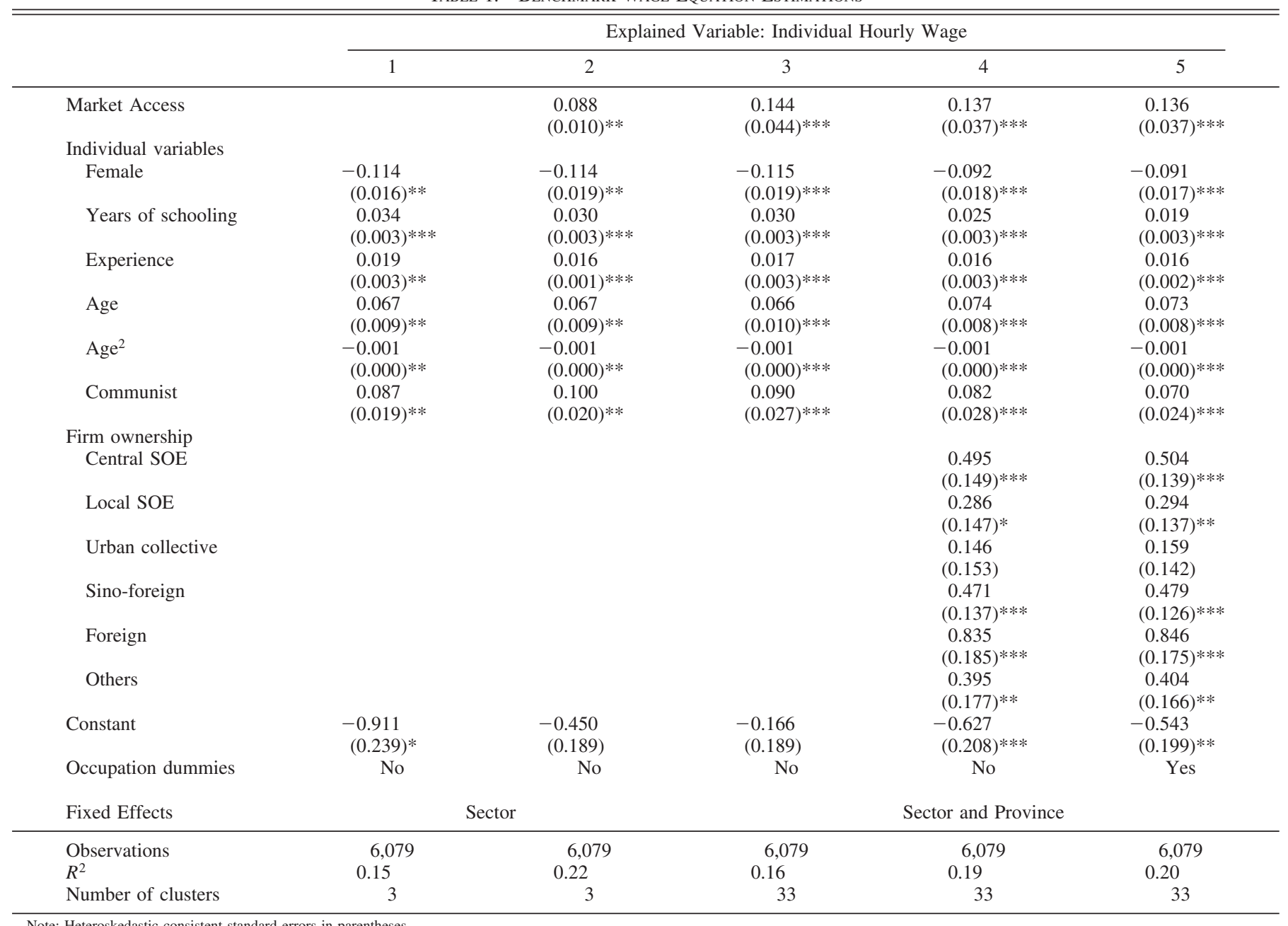

***,**, and * indicate significance at the $1 \%, 5 \%$, and $10 \%$ levels, respectively. Standard errors are corrected for clustering at the industry or province-industry level. The reported $R^{2}$ is the within $R^{2}$, which indicates how much of the variation of wages within the group of sectors is explained by our regressors.

The impact of additional control variables on the estimate of our market access variable in columns 4 and 5 is negligible. However, the introduction of dummies for occupational category leads to a logical decrease in the size of our estimated returns to schooling, which is now purged by the wage premium obtained in better work positions. In the following, we will refer to the estimated wage elasticity to market access of 0.14 found in column 5 of table 1 as our benchmark figure.

The structural derivation of our market access variable from theory provides us with a theoretical interpretation of its coefficient. Theoretically, this figure corresponds to $1 / \sigma$, with $\sigma$ being a measure of product differentiation, increasing returns to scale, and the degree of competition on the market (Head \& Mayer, 2004). Our estimate of 0.14 corresponds to $\sigma=7.1$, which is in line with the results in the literature. Empirical estimates of $\sigma$ lie typically between 5 and 10, depending on the estimation methodology (ErkelRousse \& Mirza, 2002; Head \& Ries, 2001).

In his study on market access impact on individual wages in Brazil, Paillacar (2006) reports results very similar to ours. Findings of a similar magnitude of wage elasticity to market access in two countries that are quite different in terms of labor mobility could be disappointing. However, one should note that the two studies differ significantly, notably in the level of geographical aggregation. Whereas Paillacar analyzes the impact of market access at the state level (which corresponds to the provincial level in China), our study applies to a lower geographical unit, the cities. ${ }^{32}$ Findings of similar wage elasticities to market access in Paillacar and in this study are thus not incompatible with the theoretical expectation of a greater impact of market access on wages in a context of greater barriers to migration. City-level data for Brazil or a survey covering all Chinese provinces could provide definite evidence on this question.

${ }^{32}$ While one would anticipate impediments to interstate or interprovincial migration to be greater in China than in Brazil, it is less clear what to expect when comparing labor mobility between cities of the same province in China and between states in Brazil. Indeed, labor mobility is much more intense within provinces than between provinces in China. At least two-thirds of migration flows in China in the 1990s occurred within the same province (Du, Park, \& Wang, 2005). 
TABle 2.-Robustness Checks

\begin{tabular}{lllc}
\hline \hline & Market Access Variable & \multicolumn{1}{c}{ Elasticity } & $\begin{array}{c}\text { Standard } \\
\text { Deviation }\end{array}$ \\
\hline 1 & Market Access $\left(M A_{c}\right)$ & $0.136^{* * *}$ & 0.037 \\
2 & IV: Centrality & $0.158^{* * *}$ & 0.032 \\
& Hansen Test-statistic: 0.13 & Wu Hausman: 0.44 & \\
3 & $M A_{c}$ (living costs) & $0.146^{* * *}$ & 0.032 \\
4 & $M A_{c}$ (population) & $0.205^{* * *}$ & 0.062 \\
5 & Harris & $0.793^{* * *}$ & 0.310 \\
6 & Annual earnings & $0.126^{* * *}$ & 0.032 \\
\hline Note: Heteroskedastic consistent standard errors in parentheses. & \\
$* * *, * *$, and $*$ indicate significance at the $1 \%, 5 \%$, and $10 \%$ levels, respectively. & \\
\end{tabular}

So far, our results have not addressed the potential simultaneity problem. Market access, on the right-hand side of the estimated equation, is a weighted sum of all potential expenditures, including local ones. Those expenditures depend on income, and therefore on wages, raising the concern of reverse causality in the estimation. Since a positive shock to $w_{i}$ will raise $E_{c}$ and consequently increase $M A_{c}$, we rely on a twofold approach to ensure the reliability of our estimates. First, we follow Head and Mayer (2006) and instrument our market access variable by two measures of centrality. We compute Chinese centrality and international centrality at the city level as the sum of the inverted distances of each city in our sample to the center of every inhabited 1 degree $\times 1$ degree cell in the Chinese and in the world population grid, respectively. ${ }^{33}$

The coefficient of market access based on the IV estimates is shown in row 2 of table 2, which compares our benchmark figure (column 5 in table 3 , reported in row 1 in table 2) with estimates obtained from different specifications. Hansen's $J$-test of overidentifying restrictions does not significantly reject the validity of our instruments. ${ }^{34} \mathrm{We}$ find that the IV estimate is not significantly different from the benchmark figure obtained with OLS. ${ }^{35}$

Our second focus is on the potential bias induced by our ad hoc allocation rule. We therefore recompute market access to check the appropriateness of using GDP shares to calculate the local and provincial component of market access. Rows 3 and 4 display the results when population or living expenditures instead of GDP are used to apportion provincial market capacity. These results are similar to those obtained before and strengthen our confidence in the results of the benchmark estimation.

Row 5 replaces market access by the Harris (1954) measure of market potential, defined as $\sum_{j} E_{c} / d i s t_{c j}$. This indicator, which has frequently been used in empirical work because of its ease of calculation, is typically found to have a larger coefficient than structural estimates of MA. Our finding of a higher wage elasticity with Harris market potential than our market access measure is thus consistent with the existing literature (Head \& Mayer, 2006).

\footnotetext{
${ }^{33}$ For more details on the instruments, see Head and Mayer (2006).

${ }^{34}$ Significance is judged at the $10 \%$ confidence level.

${ }^{35}$ The Wu-Hausman test does not reject the null hypothesis of exogeneity of our market access variable at the $10 \%$ confidence level.
}

In the last row, we report our estimates using total annual wages as the dependent variable. The results remain the same, suggesting that controlling for working hours does not alter the estimated impact of market access on wages.

All of the estimates in table 2 correspond to a value of $\sigma$ between 5 (the value typically used in Krugman's illustrations of NEG) and 10. The only exception is found for the Harris measure, which does not, however, retain the structural interpretation of the coefficient on log market potential.

Having found a theoretically consistent, positive, and significant impact of market access on hourly wages, we can conclude that the wage disparities within provinces partly reflect differences in cities' market access. Growing differences in trade costs or market sizes between cities can therefore increase intraprovincial wage disparities.

\section{B. Market Access, Size Effect, and Other Controls}

According to the above estimates, we might conclude that the spatial variation of wages in China is consistent with our NEG model. However, since our only variable at the city level is market access, its impact could also capture features consistent with urban agglomeration theories. Hanson (2003) distinguishes three additional mechanisms apart from market access linking agglomeration and wages: nonhuman factor endowments, increasing returns external to firms, and human capital externalities. With respect to the first mechanism, we continue to assume that differences in institutions and technology are more likely to occur at the provincial and industry levels and do not control for local differences. The second and third mechanisms correspond to two main competing dynamics relating to agglomeration. On the one hand, the larger or denser is an agglomeration (in terms of labor), the more knowledge spillovers there are between firms and workers. This leads to higher worker productivity and therefore higher wages. On the other hand, large agglomerations often exert downward pressure on prices because of tougher competition between a greater number of producers. A lower price level drives down wages. Big cities are therefore exposed to these two contradictory forces.

So far, we have insufficiently controlled for these aspects. It is thus possible that our significant market access result captures the size effect caused by spillovers between firms or human capital externalities. The regression in column 1 of table 3 introduces the natural logarithm of the local population as a proxy for city size. The impact of $M A_{c}$ stays unchanged, whereas population is insignificant. This might be due to the fact that the two competing forces presented above cancel each other out.

In the second column, we introduce a proxy for the city's human capital stock. This indicator, skill intensity, is computed as the city's share of individuals in the survey having completed at least nine years of schooling (which corresponds in general to the end of lower middle school). Its 
TAble 3.-Market Access versus Urban Agglomeration Theory

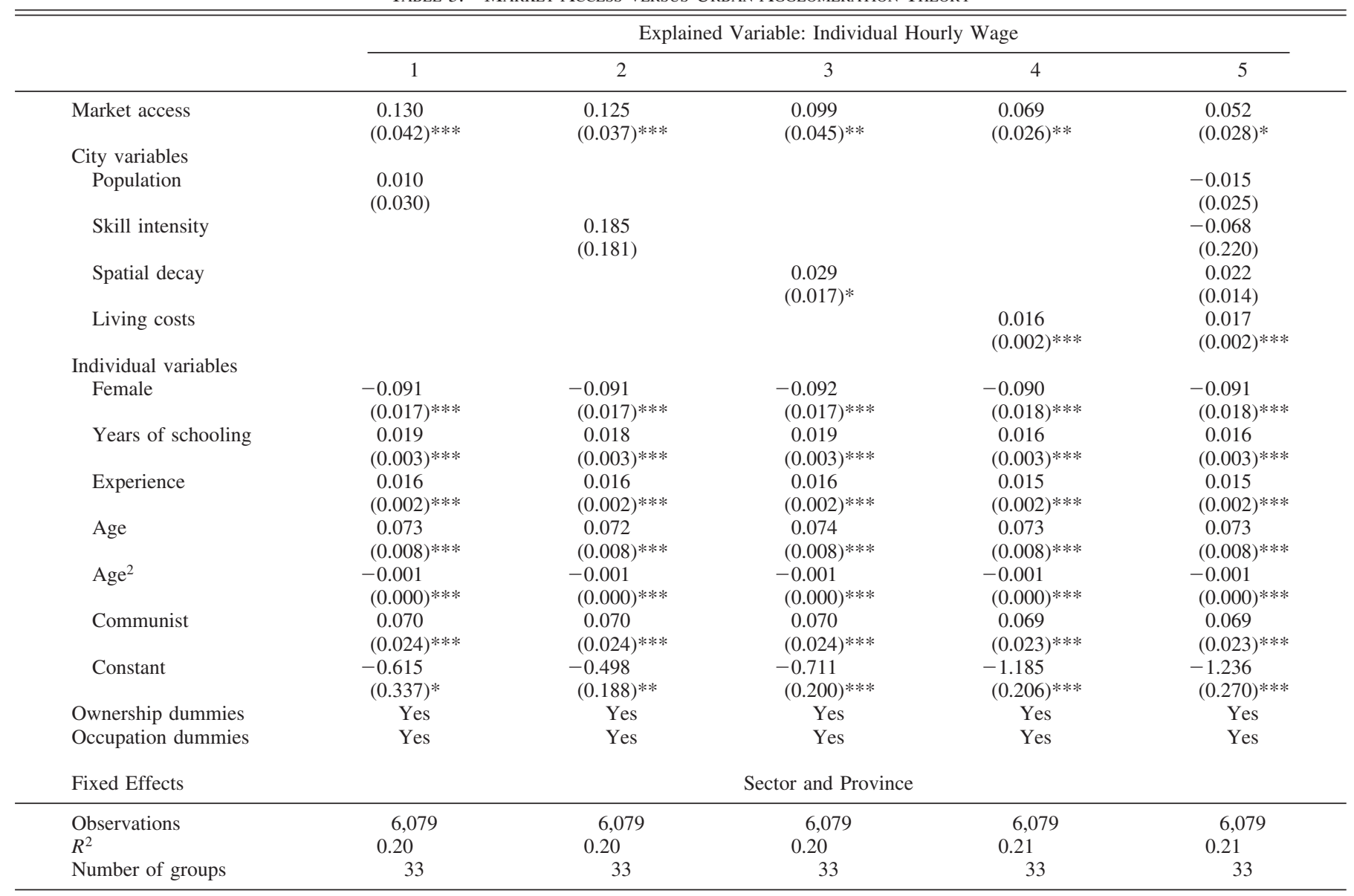

Note: Heteroskedastic consistent standard errors in parentheses.

***,**, and * indicate significance at the $1 \%, 5 \%$, and $10 \%$ levels, respectively. Standard errors are corrected for clustering at the industry or province-industry level. The reported $R^{2}$ is the within $R^{2}$, which indicates how much of the variation of wages within the group of sectors is explained by our regressors.

coefficient is positive but insignificant, while the coefficient of $M A_{c}$ remains unaffected.

In column 3 of table 3 , we let the market access variable compete with an indicator of human capital externalities with spatial decay. ${ }^{36}$ The indicator spatial decay for each city is constructed as the distance-weighted sum of the population share enrolled in middle school over all cities of the same province, including itself. ${ }^{37}$ While the indicator enters with a positive and significant sign, attesting to the presence of positive human capital externalities on individual wages, it does not alter our original results. We conclude that our results confirm the validity of NEG theory in China even after scale and human capital effects have been accounted for.

Finally, we investigate the possibility that the impact of $M A_{c}$ on nominal wages is due to the provision by firms of greater subsidies for housing and other living costs (required by workers to accommodate higher living costs due

\footnotetext{
${ }^{36}$ We thank an anonymous referee for this suggestion.

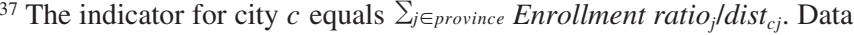
come from the Urban Statistical Yearbook, published by China's State Statistical Bureau.
}

to agglomeration effects) instead of higher salaries reflecting the increase in profits due to lower transportation costs.

Besides the effect emphasized by the NEG (firms in locations with higher market access incur lower overall transportation costs and thus are able to pay higher wages), Dekle and Eaton (2002) propose an alternative mechanism relying on agglomeration economics that might explain the positive impact of market access on wages. It could be the case that greater demand pushes up the price of land (or other immobile inputs) and thus induces firms to raise nominal wages to maintain workers' purchasing power. While theoretically both effects are combined in our model, since labor is the only immobile factor, it is empirically important to account for this channel. We include in column 4 a proxy for city-level living costs, living costs, calculated as the average of the values reported in the survey on the monthly cost of maintaining a minimum standard of living for the household.

This indicator enters positively and significantly, leading to a reduction in the size and significance of our market access variable. However, this does not change the flavor of our results. The coefficient of 0.016 indicates that an in- 
TAble 4.-Market Access and Wages: The EfFect of Education

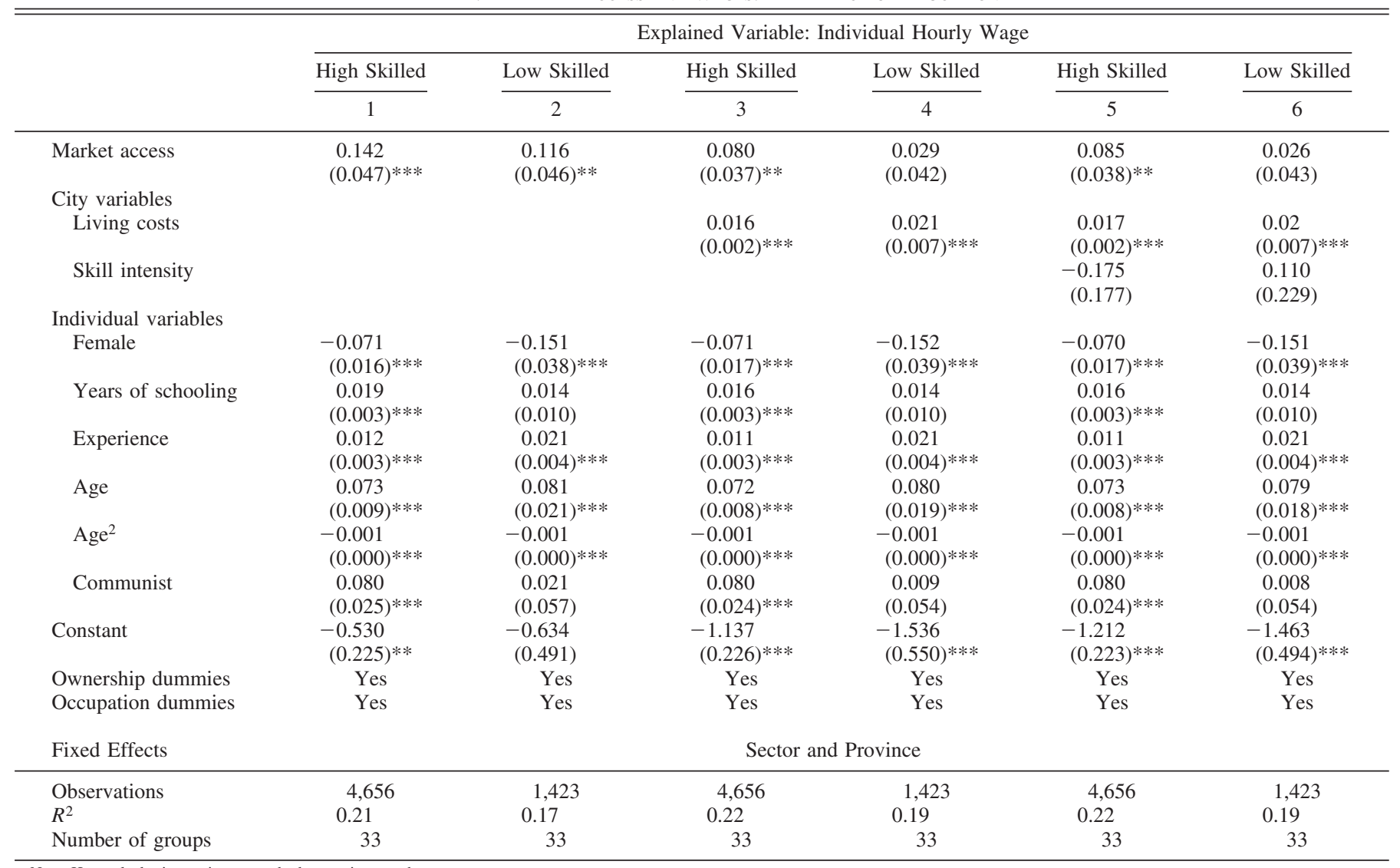

Note: Heteroskedastic consistent standard errors in parentheses.

$* * * * *$, and $*$ indicate significance at the $1 \%, 5 \%$, and $10 \%$ levels, respectively. Standard errors are corrected for clustering at the industry or province-industry level. The reported $R^{2}$ is the within $R^{2}$, which indicates how much of the variation of wages within the group of sectors is explained by our regressors.

crease of 1 standard deviation in living costs ${ }^{38}$ leads to an increase of $12 \%$ in wages. This corresponds to an increase of 55 yuan over the average monthly wage of 465 yuan.

In the last column, we combine the impact of all four variables. Here also the coefficient on $M A_{c}$ remains significant, although only at the $10 \%$ level.

\section{Heterogeneous Influence of Market Access}

One novel contribution of our paper is to investigate the possibility that the relationship between market access and wages depends on workers' skills and firm ownership types.

Market Access Impact: Skills Matter. In table 4, we run separate regressions for high-skilled and low-skilled workers. An individual is considered high skilled if he or she has completed at least nine years of schooling; otherwise the individual is classified as a low-skilled worker. In a comparison of columns 1 and 2, the impact of market access does not seem to be significantly different between these two groups, even though the coefficient is lower and sig-

\footnotetext{
${ }^{38}$ An increase of 1 standard deviation corresponds to a rise in the living cost index of 72 yuan per month.
}

nificant only at the 5\% level for low-skilled wage earners. In the next four columns, we introduce living costs and the city's percentage of skilled workers. We see that once we control for living costs, the wages of high-skilled workers rise significantly with market access, whereas the coefficient of $M A_{c}$ for low-skilled workers becomes insignificant. This indicates that although nominal wages increase with market access for all workers, as seen in columns 1 and 2, the increase for low-skilled workers corresponds mainly to the increase in living costs. Thus, these results suggest that a rise in market access leads to an increase in wages in real terms only for high-skilled workers.

The comparison of columns 1 and 2 indicates that the determinants of wages differ between the two groups. Notably there seems to be no return to schooling and no wage premium from Communist Party membership for unskilled workers. Furthermore, the gender-wage gap seems to be reduced for the highly skilled.

We argue that high-skilled workers are likely to benefit differentially from market access because they are less at risk from migrants who in the majority have low skills. Surveys on migrants to cities in China stress that the segregation of workers according to their residence permit 
(hukou) makes it difficult for rural residents to find formal employment in urban areas. ${ }^{39}$ Park, Zhao, and Huang (2006) find a strong effect of hukou status on the occupational choice of nonagricultural workers. Most of these can find only jobs that are temporary and physically demanding (Cai \& Wang, 2003).

The finding of a larger effect of market access on wages for skilled workers is thus consistent with the NEG model, which predicts that the relationship between market access and wages will be weaker as migration is stronger. This relates to the two mechanisms by which the local economy can adjust to a change in the demand for its goods: quantitative adjustment, with new workers filling in positions to meet the additional demand, or, in the case of insufficient labor mobility, adjustment achieved by a change in prices, which means that wages will rise with market access.

Our results suggest that the first mechanism is stronger in the case of low-skilled jobs and a highly competitive labor market. Regulations such as governmental prohibition of enterprises from hiring migrants in certain jobs and posts may protect skilled workers to a greater extent.

Market Access Impact: The Influence of Firm Ownership. In 1995, while the number of private firms started to grow rapidly, a very high percentage of registered employment was still in publicly owned enterprises. ${ }^{40}$ When looking at the interaction between $M A_{c}$ and firm ownership, we would expect different impacts for different types of ownership: private, recently created firms should be more flexible in terms of wages and react more to market shocks than state-owned firms. This intuition is confirmed by the results reported in table 5. Here, we interact $M A_{c}$ with firm ownership dummies in order to see whether the impact of market access varies across different firm types.

We find that, on the one hand, wages in foreign-owned firms react more strongly to changes in market access than do those in other firm types. On the other hand, there is a significantly lower-than-average impact of $M A_{c}$ on wages for SOEs, whether they are owned at the central or the local level. The extremely high sensitivity of wages to market access in the case of foreign-owned firms should be handled with care, since the number of observations in this group is very small.

When living costs are introduced into the regression, nearly all market access coefficients fall, and the estimates for central SOEs and "others" become insignificant, indicating that in these firms, nominal wages increase only to

\footnotetext{
${ }^{39}$ A full description of labor market conditions and migration patterns within China (across and within provinces) is beyond the scope of this paper. Interested readers should refer to Cai, Park, and Zhao (2007) an Du et al. (2005). Data from the 1995 population census indicate that intraprovincial migration to cities is a major component of migration across China: 17.3 million people engaged in intraprovincial migration to cities between 1990 and 1995 . This corresponds to $52 \%$ of total migration flows recorded within and between provinces over the period.

40 Out of our 6,079 individuals, 4,611 work in either central or local SOEs.
}

Table 5.-Market Access and Wages: The Effect of Firm Ownership

\begin{tabular}{|c|c|c|c|}
\hline & \multicolumn{3}{|c|}{$\begin{array}{c}\text { Explained Variable: Individual Wage } \\
\text { per Hour }\end{array}$} \\
\hline & 1 & 2 & 3 \\
\hline \multicolumn{4}{|l|}{ Market access } \\
\hline MA $\times$ Foreign & $\begin{array}{l}0.511 \\
(0.075)^{* * *}\end{array}$ & $\begin{array}{l}0.539 \\
(0.085)^{* * * *}\end{array}$ & $\begin{array}{l}0.539 \\
(0.082)^{* * *}\end{array}$ \\
\hline MA $\times$ Private & $\begin{array}{l}0.197 \\
(0.056)^{* * *}\end{array}$ & $\begin{array}{l}0.127 \\
(0.051)^{* *}\end{array}$ & $\begin{array}{l}0.128 \\
(0.052)^{* *}\end{array}$ \\
\hline MA $\times$ Sino-foreign & $\begin{array}{l}0.158 \\
(0.038) * * *\end{array}$ & $\begin{array}{l}0.096 \\
(0.032)^{* * * *}\end{array}$ & $\begin{array}{l}0.098 \\
(0.032)^{* * *}\end{array}$ \\
\hline MA $\times$ Urban collective & $\begin{array}{l}0.151 \\
(0.030)^{* * *}\end{array}$ & $\begin{array}{l}0.086 \\
(0.020)^{* * *}\end{array}$ & $\begin{array}{l}0.088 \\
(0.021)^{* * *}\end{array}$ \\
\hline MA $\times$ Local SOE & $\begin{array}{l}0.137 \\
(0.034)^{* * *}\end{array}$ & $\begin{array}{l}0.068 \\
(0.023)^{* * *}\end{array}$ & $\begin{array}{l}0.071 \\
(0.024) * * *\end{array}$ \\
\hline MA $\times$ Others & $\begin{array}{l}0.130 \\
(0.049)^{* * *}\end{array}$ & $\begin{array}{l}0.064 \\
(0.041)\end{array}$ & $\begin{array}{c}0.066 \\
(0.042)\end{array}$ \\
\hline $\mathrm{MA} \times$ Central SOE & $\begin{array}{l}0.104 \\
(0.049)^{* *}\end{array}$ & $\begin{array}{c}0.042 \\
(0.035)\end{array}$ & $\begin{array}{l}0.045 \\
(0.035)\end{array}$ \\
\hline \multicolumn{4}{|l|}{ City variables } \\
\hline Living costs & & $\begin{array}{l}0.017 \\
(0.002)^{* * * *}\end{array}$ & $\begin{array}{l}0.017 \\
(0.002)^{* * *}\end{array}$ \\
\hline Skill intensity & & & $\begin{array}{r}-0.070 \\
(0.185)\end{array}$ \\
\hline \multicolumn{4}{|l|}{ Individual variables } \\
\hline Female & $\begin{array}{l}-0.091 \\
(0.017)^{* * *}\end{array}$ & $\begin{array}{l}-0.090 \\
(0.018)^{* * *}\end{array}$ & $\begin{array}{l}-0.090 \\
(0.018) * * *\end{array}$ \\
\hline Years of schooling & $\begin{array}{l}0.018 \\
(0.003)^{* * *}\end{array}$ & $\begin{array}{l}0.016 \\
(0.003)^{* * *}\end{array}$ & $\begin{array}{l}0.016 \\
(0.003) * * *\end{array}$ \\
\hline Experience & $\begin{array}{l}0.016 \\
(0.002)^{* * * *}\end{array}$ & $\begin{array}{l}0.015 \\
(0.002)^{* * *}\end{array}$ & $\begin{array}{l}0.015 \\
(0.002)^{* * *}\end{array}$ \\
\hline Age & $\begin{array}{l}0.073 \\
(0.008) * * *\end{array}$ & $\begin{array}{l}0.073 \\
(0.008)^{* * *}\end{array}$ & $\begin{array}{l}0.073 \\
(0.007) * * *\end{array}$ \\
\hline $\mathrm{Age}^{2}$ & $\begin{array}{l}-0.001 \\
(0.000)^{* * *}\end{array}$ & $\begin{array}{l}-0.001 \\
(0.000)^{* * *}\end{array}$ & $\begin{array}{l}-0.001 \\
(0.000)^{* * *}\end{array}$ \\
\hline Communist & $\begin{array}{l}0.073 \\
(0.024)^{* * *}\end{array}$ & $\begin{array}{l}0.072 \\
(0.023)^{* * *}\end{array}$ & $\begin{array}{l}0.072 \\
(0.023) * * *\end{array}$ \\
\hline Constant & $\begin{array}{c}-0.332 \\
(0.236)\end{array}$ & $\begin{array}{l}-0.987 \\
(0.262)^{* * *}\end{array}$ & $\begin{array}{l}-1.025 \\
(0.232) * * *\end{array}$ \\
\hline Ownership dummies & Yes & Yes & Yes \\
\hline Occupation dummies & Yes & Yes & Yes \\
\hline
\end{tabular}

Fixed Effects

Sector and Province

$\begin{array}{lccc}\text { Observations } & 6,079 & 6,079 & 6,079 \\ R^{2} & 0.20 & 0.22 & 0.22 \\ \text { Number of groups } & 33 & 33 & 33 \\ \text { Private = Central SOE } & 3.98^{*} & 3.31^{*} & 3.35^{*} \\ \text { Private = Foreign } & 14.22 * * * & 18.98^{* * *} & 19.66^{* * *} \\ \text { Local SOE = Foreign } & 23.48^{* * *} & 27.97 * * * & 29.75^{* * *}\end{array}$

Note: Heteroskedastic consistent standard error in parentheses.

***,**, and * indicate significance at the $1 \%, 5 \%$, and $10 \%$ levels, respectively. Standard errors are corrected for clustering at the industry or province-industry level. The reported $R^{2}$ is the within $R^{2}$, which indicates how much of the variation of wages within the group of sectors is explained by our regressors.

keep workers' purchasing power constant. These results are robust to the introduction of other control variables. The tests at the bottom of the table highlight the existence of a significant difference between firm ownership types.

Wages in foreign firms react the most strongly to variations in demand, followed by private, Sino-foreign, urban collective, others, and publicly owned enterprises. This hierarchy is consistent with work on the structure of the Chinese economy, which emphasizes the coexistence of enterprises facing very different institutional and economic environments. While employment and wage setting in nonstate enterprises are mainly driven by market forces, SOEs still operate according to the central administration plan and 
are characterized by overstaffing (Lin, Cai, \& Li, 2001). The lower impact of market access on wages in these enterprises might be explained by their worker surplus, as in the event of a rise in demand, they can resort to their underemployed workers. The adjustment is internal to the firm and occurs without resorting to new employment or paying high overtime wages (Knight \& Song, 2005).

\section{Conclusion}

This paper has examined the impact of economic geography on the spatial structure of wages in China. It has attempted to explain interindividual wage differences by the individual's location proximity to markets. We control for gender and age as well as individual skills in terms of experience and education, which are expected to explain an important part of spatial wage variations. Following the literature pointing out the importance of factor endowments in spatial wage disparities, province and sector fixed effects and proxies for living costs and human capital externalities are introduced. Even after controlling for these factors, the relationship between the city's market access, calculated using a gravity equation, and individual Chinese wages is positive and significant.

The finding of a significant impact of market access on individual wage data validates the pioneering results of Redding and Venables (2004) on aggregate data and justifies the inclusion of this variable in research on wage differentials. Our results also highlight that the impact of $M A_{c}$ cannot be generalized, since the relationship between market access and wages holds only for high-profile workers and for certain firm types. Wages earned in foreign firms, and to a lesser extent in private and Sino-foreign firms, react strongly to changes in $M A_{c}$, while wages in central SOEs seem to be largely insensitive to them when controlling for living costs. This means that, probably due to the remnants of central economic planning, the impact of market access is limited in the Chinese economy. We conclude that interregional and intraprovincial wage disparities likely partly reflect differences in market access. Considering that market access also has a significant international component, it is likely that with further integration into the world economy, these disparities will grow if access to new markets is not evenly distributed across the country. Our results here suggest that any further opening of the country, without increasing liberalization of internal migration, may worsen the already pervasive spatial wage disparities. Nevertheless, the impact of market access could change over time. More research with data spanning a number of years is needed to ascertain the evolution of wages in response to changing market access. An important issue is whether the relaxation of restrictions on internal migration will eventually mitigate the segmentation of the labor market and dampen the impact of market access, promoting the equalization of wages across the Chinese territory for given skills and factor endowments.

\section{REFERENCES}

Amiti, Mary, and Lisa Cameron, "Economic Geography and Wages," this REVIEW 89:1 (2007), 15-29.

Amiti, Mary, and Beata S. Javorcik, "Trade Costs and Location of Foreign Firms in China," Journal of Development Economics 85:1-2 (2008), 194-217.

Baldwin, Richard, Rikard Forslid, Philippe Martin, Gianmarco Ottaviano, and Frederic Robert-Nicoud, Economic Geography and Public Policy (Princeton, NJ: Princeton University Press, 2003).

Banister, Judith, "Manufacturing Employment and Compensation in China," consultant's report to U.S. Department of Labor, Bureau of Labor Statistics (2005).

Bernard, Andrew B., Steven J. Redding, and Peter K. Schott, "Factor Price Equality and the Economies of the United States," CEPR discussion paper no. 5111 (2005).

Brakman, Steven, Harry Garretsen, and Marc Schramm, "The Spatial Distribution of Wages and Employment: Estimating the HelpmanHanson Model for Germany," Journal of Regional Science 44:3 (2004), 437-466.

Breinlich, Holger, "The Spatial Income Structure in the European Union: What Role for Economic Geography?" Journal of Economic Geography 6:5 (2006), 593-617.

Cai, Fang, Albert Park, and Yaohui Zhao, "The Chinese Labor Market in the Reform Era," in Loren Brandt and Thomas Rawski (Eds.), China's Great Economic Transformation (Cambridge: Cambridge University Press, 2007).

Cai, Fang, and D. Wang, "Impacts of Internal Migration on Economic Growth and Urban Development in China," CASS working paper (2003).

Chen, Yi, Sylvie Démurger, and Martin Fournier, "Earnings Differentials and Ownership Structure in Chinese Enterprises," Economic Development and Cultural Change 53:4 (2005), 933-958.

"The Evolution of Gender Earnings Gaps and Discrimination in Urban China, 1988-95," Developing Economies 54:1 (2007), 97121.

Combes, Pierre-Philippe, Gilles Duranton, and Laurent Gobillon, "Spatial Wage Disparities: Sorting Matters!" Journal of Urban Economics 63:2 (2008), 732-742.

De Bruyne, Karolien, "The Location of Economic Activity: Is There a Spatial Employment Structure in Belgium?" K. U. Leuven mimeograph (2003).

Dekle, Robert, and Jonathan Eaton, "Agglomeration and Land Rents: Evidence from the Prefectures," Journal of Urban Economics 46:2 (2002), 200-214.

Dixit, Avinash K., and Joseph E. Stiglitz, "Monopolistic Competition and Optimum Product Diversity," American Economic Review 67:3 (1977), 297-308.

Du, Yang, Albert Park, and Sangui Wang, "Migration and Rural Poverty in China," Journal of Comparative Economics 33:4 (2005), 688-709.

Erkel-Rousse, Hélène, and Daniel Mirza, "Import Elasticities: Reconsidering the Evidence," Canadian Journal of Economics 35:2 (2002), 282-306.

Feenstra, Robert C., Wen Hai, Wing T. Woo, and Shunli Yao, "The U.S.-China Bilateral Trade Balance: Its Size and Determinants," NBER working paper no. W6598 (1998).

Fujita, Masahisa, Paul Krugman, and Anthony J. Venables, The Spatial Economy: Cities, Regions and International Trade (Cambridge, MA: MIT Press, 1999).

Hadi, Ali S., "A Modification of a Method for the Detection of Outliers in Multivariate Samples," Journal of the Royal Statistics Society 56:B (1994), 393-396.

Hanson, Gordon H., "Firms, Workers, and the Geographic Concentration of Economic Activity," in Gordon L. Clark, Meric S. Gertler, and Maryann P. Feldman (Eds.), The Oxford Handbook of Economic Geography (New York: Oxford University Press, 2003).

"Market Potential, Increasing Returns, and Geographic Concentration," Journal of International Economics 67:1 (2005), 1-24.

Harris, Chauncy D., "The Market as a Factor in the Localization of Industry in the United States," Annals of the Association of American Geographers 64 (1954), 315-348.

Head, Keith, and Thierry Mayer, "The Empirics of Agglomeration and Trade," in J. Vernon Henderson and Jacques-François Thisse 
(Eds.), Handbook of Regional and Urban Economics, Vol. 4 (Amsterdam: Elsevier, 2004).

"Regional Wage and Employment Responses to Market Potential in the EU," Regional Science and Urban Economics 36:5 (2006), 573-594.

Head, Keith, and John Ries, "Increasing Returns Versus National Product Differentiation as an Explanation for the Pattern of US-Canada Trade," American Economic Review 91:4 (2001), 858-876.

Heckman, James J., "The Common Structure of Statistical Models of Truncation, Sample Selection, and Limited Dependent Variables and a Simple Estimator for Such Models," Annals of Economic and Social Measurement 5 (1976), 475-492.

Knight, John, and Lina Song, Towards a Labour Market in China (New York: Oxford University Press, 2005).

Krugman, Paul, "Scale Economies, Product Differentiation and the Pattern of Trade," American Economic Review 70:5 (1980), 950-959.

"Increasing Returns and Economic Geography," Journal of Political Economv 99:3 (1991), 483-499.

Krugman, Paul, and Anthony J. Venables, "Globalization and the Inequality of Nations," Ouarterly Journal of Economics 110:4 (1995), 857-880.

Li, Haizheng, "Economic Transition and Returns to Education in China," Economics of Education Review 22:3 (2003), 317-328.

Lin, Justin Y., Fang Cai, and Zhou Li, State-Owned Enterprise Reform in China (Hong King: Chinese University Press, 2001).

Lin, Songhua, "Geographic Location, Trade and Income Inequality in China," in Ravi Kanbur and Anthony J. Venables (Eds.), Spatial Inequality and Development (New York: Oxford University Press, 2005).

Ma, Alyson C., "Geographical Location of Foreign Direct Investment and Wage Inequality in China," World Economy 29:8 (2006), 10311055 .

Meng, Xin, Robert Gregory, and Youjuan Wang, "Poverty, Inequality and Growth in Urban China, 1986-2000," Journal of Comparative Economics 33:4 (2005), 710-729.

Mincer, Jacob, Schooling, Experience and Earnings (New York: Columbia University Press, 1974).

Mion, Giordano, "Spatial Externalities and Empirical Analysis: The Case of Italy," Journal of Urban Economics 56:1 (2004), 97-118.

Mion, Giordano, and Paolo Naticchioni, "Urbanization Externalities, Market Potential and Spatial Sorting of Skills and Firms," CEPR discussion paper 5172 (2005).

Moulton, Brent R., "Random Group Effects and the Precision of Regression Estimates," Journal of Econometrics 32:3 (1986), 385-397.

"An Illustration of a Pitfall in Estimating the Effects of Aggregate Variables on Micro Units," this REVIEw 72:2 (1990), 334-338.

Paillacar, Rodrigo, "Market Potential and Worker Heterogeneity as Determinants of Brazilian Wages," University of Paris 1 mimeograph (2006).

Park, Albert, Yaohui Zhao, and Guofang Huang, "Migrant Workers and Labor Market Segmentation in Urban China," manuscript (2006),

Ping, Huang, and Frank N. Pieke, "China Migration Country Study," paper presented at the DFID/RMMRU Conference on Migration Development Pro-Poor Policy Choices in Asia, Dhaka, June 22-24 (2003).

Poncet, Sandra, "Measuring Chinese Domestic and International Integration?" China Economic Review 14:1 (2003), 1-22.

"A Fragmented China: Measure and Determinants of China's Domestic Market Disintegration," Review of International Economics 13:3 (2005), 409-430.

Psacharopoulos, George, "Returns to Investment in Education: A Global Update," World Development 22:9 (1994), 1325-1343.

Ravallion, Martin, and Shaohua Chen, "China's (Uneven) Progress against Poverty," Journal of Development Economics 82:1 (2007), $1-42$.

Redding, Stephen J., and Peter K. Schott, "Distance, Skill Deepening and Development: Will Peripheral Countries Ever Get Rich?" Journal of Development Economics 72:2 (2003), 515-541.

Redding, Stephen J., and Anthony J. Venables, "South-East Asian Export Performance: External Market Access and Internal Supply Capacity," Journal of the Japanese and International Economies 17:4 (2003), 404-441.

"Economic Geography and International Inequality," Journal of International Economics 62:1 (2004), 53-82.
Riskin, Carl, Renwei Zhao, and Shi Li, Chinese Household Income Project, 1995 [Computer file]. ICPSR version. Amherst, MA: University of Massachusetts, Political Economy Research Institute [producer], 2000. China's Retreat from Equality Income Distribution and Economic Transition (London: M. E. Sharpe, 2001).

Rogers, William, "Regression Standard Errors in Clustered Samples," Stata Technical Bulletin 13 (1993), 19-23.

State Statistical Bureau, China Statistical Yearbook (Beijing: China Statistical Bureau, various issues).

Wei, Shang-Jin, "Intra-National Versus International Trade: How Stubborn Are Nations in Global Integration," NBER working paper no. 5531 (1996).

Wei, Shang-Jin, and Yi Wu, "Globalization and Inequality without Differences in Data Definition, Legal System and Other Institutions," International Monetary Fund working paper (October 2002).

Willis, Robert J., "Wage Determinants: A Survey and Reinterpretation of Human Capital Earnings Functions," in Orley C. Ashenfelter and Richard Layard (Eds.), Handbook of Labor Economics, Vol. 1 (Amsterdam: North Holland, 1986).

Zhao, Yaohui, "Earnings Differentials between State and Non-State Enterprises in Urban China," Pacific Economic Review 7:1 (2002), 181-197.

\section{APPENDIX A}

Map A1.-Provincial Market Capacities

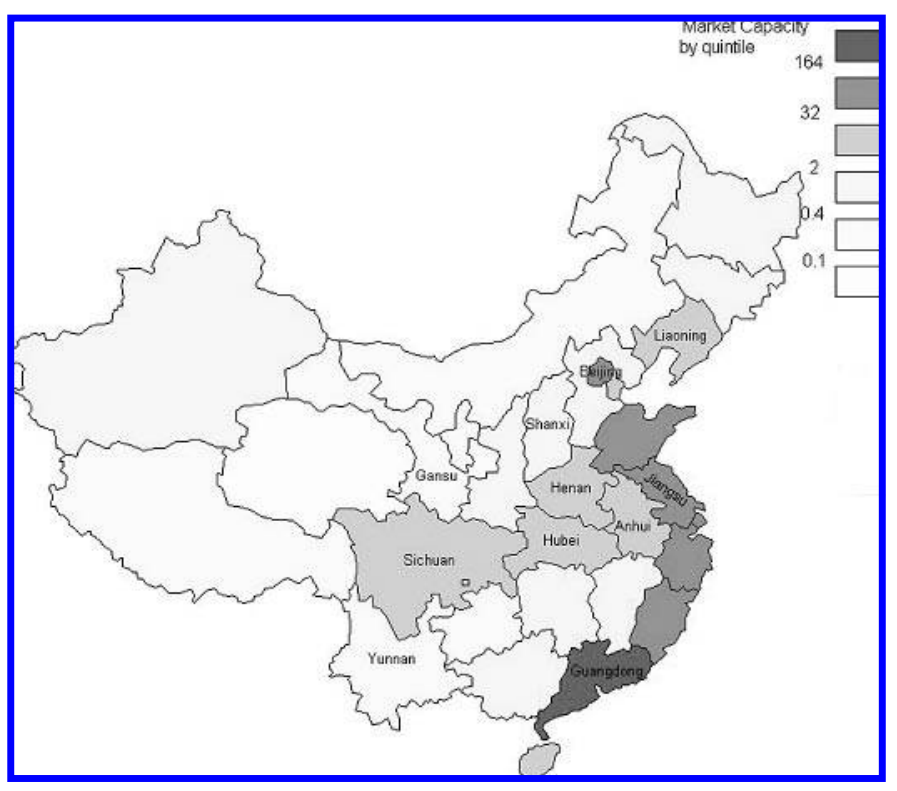

Made with Philcarto—http://perso.club-internet.fr/philgeo.

TABLE A1.-CITIES

\begin{tabular}{ll}
\hline \hline \multicolumn{1}{c}{ Provinces } & \\
\hline Beijing & Beijing \\
Shanxi & Changzhit, Datong, Fenyang, Taiyuan, Yangquan \\
Liaoning & Dalian, Jinzhou, Shenyang \\
Jiangsu & Changzhou, Dafeng, Nanjing, Nantong, Suqian, Taixing, \\
& Wuxi, Xuzhou, Yixing \\
Anhui & Bengbu, Bozhou, Hefei, Huainan, Tongcheng, Wuhu \\
Henan & Huixian, Kaifeng, Pingdingshan, Xiangcheng, Xinxiang, \\
& Zhengzhou \\
Hubei & Honghu, Huangshi, Macheng, Tianmen, Wuhan, Xiangfan \\
Guangdong & Foshan, Guangzhou, Huizhou, Puning, Shenzhen, Shunde, \\
Sichuan & Zhanjiang, Zhaoqing \\
Yunnan & Chengdu, Guangyuan, Leshan, Luzhou, Zigong \\
Gansu & Lani, Gejiu, Kunming, Xuanwei \\
\hline
\end{tabular}


Table A2.-Descriptive Statistics for Hourly Wages (in Yuan) by Province

\begin{tabular}{|c|c|c|c|c|c|c|}
\hline & All & Beijing & Shanxi & Liaoning & Jiangsu & Anhui \\
\hline Observations & 6,079 & 402 & 537 & 701 & 872 & 511 \\
\hline Mean & 2.99 & 3.72 & 2.50 & 3.13 & 3.05 & 2.48 \\
\hline Standard deviation & 4.26 & 1.91 & 1.45 & 5.82 & 1.85 & 2.42 \\
\hline \multirow[t]{2}{*}{ Median } & 2.5 & 3.55 & 2.21 & 2.48 & 2.72 & 2.07 \\
\hline & Henan & Hubei & Guangdong & Sichuan & Yunnan & Gansu \\
\hline Observations & 495 & 601 & 558 & 710 & 396 & 296 \\
\hline Mean & 2.22 & 2.76 & 5.13 & 2.76 & 2.62 & 1.97 \\
\hline Standard deviation & 2.15 & 1.75 & 10.90 & 2.06 & 1.08 & 1.54 \\
\hline Median & 1.83 & 2.46 & 3.99 & 2.35 & 2.51 & 1.62 \\
\hline
\end{tabular}

Table A3.-Trade Equation Estimations

\begin{tabular}{lc}
\hline \hline & Explained Variable: \\
Ln (Exports) in 1997 \\
\hline Ln distance & -1.528 \\
& $(0.024)^{* * *}$ \\
Contiguity & 1.162 \\
& $(0.123)^{* * *}$ \\
Interforeign country & -1.731 \\
border effect & $(0.320)^{* * * *}$ \\
China-foreign country & -3.681 \\
border effect & $(0.353)^{* * *}$ \\
Intra-China border & -2.766 \\
effect & $(0.780)^{* * *}$ \\
Constant & 19.488 \\
& $(0.440)^{* * *}$ \\
& \\
Fixed Effects & Exporter and Importer \\
\hline Observations & 22,290 \\
Number of importers & 270 \\
Within $R^{2}$ & 0.59 \\
\hline
\end{tabular}

Note: Heteroskedastic consistent standard errors in parentheses.

*** Significance at the $1 \%$ level.

\section{APPENDIX B}

\section{Data}

International trade flows are in current USD. These are obtained from the IMF Direction of Trade Statistics (DOTS).

Internal trade flows are in current USD and are calculated as the difference between domestic primary and secondary sector production minus exports. Production data for OECD countries come from the OECD STAN database. For other countries, ratios of industry and agriculture output in percentages of GDP are extracted from Datastream. They are then multiplied by the countries' GDP (in current USD) from World Development Indicators 2005.

Intraprovincial trade flows for China and intranational trade flows for foreign countries are computed, following Wei (1996), as domestic production minus total exports. Total production for Chinese provinces is computed as the sum of industrial and agricultural output. Output in yuan is converted into current USD using the annual exchange rate. All statistics come from the China Statistical Yearbook (various years).
TABLE A4.-Summary Statistics

\begin{tabular}{lcrr}
\hline \hline \multicolumn{1}{c}{ Variables } & \multicolumn{1}{c}{ Mean } & Median & \multicolumn{1}{c}{ S.D. } \\
\hline Market access & 0.072 & 0.006 & 0.15 \\
Years of schooling & 10.25 & 10 & 2.72 \\
Experience & 19.13 & 20 & 19.14 \\
Age & 35.95 & 39 & 9.26 \\
Age & $1,526.08$ & 1,521 & 702.99 \\
Female & 0.47 & 0 & 0.50 \\
Communist & 0.1845 & 0 & 0.39 \\
\hline
\end{tabular}

Provincial input-output (IO) tables provide the decomposition of provincial output, international and domestic trade of tradable goods. ${ }^{41}$ Domestic trade flows, that is trade between each province and the rest of China, were obtained for 1997.42 The rest of China, denoted by roC, is different for each province considered and can be thought of as a distinct country whose characteristics (distance to partners dist $t_{r-r o C}$ ) are generated from the characteristics of the provinces that make it up. See Poncet (2005) for more details.

The provincial foreign trade data are obtained from the Customs General Administration database, which records the value of all of the import or export transactions through customs. Provincial imports and exports are decomposed into up to 230 international partners. We rely on data for 1997. The database is discussed in Lin (2005) and Feenstra et al. (1998). Statistics on GDP, land area and population at the city and province level come mainly from two sources: the Urban Statistical Yearbook, various issues, published by China's State Statistical Bureau, and China City Statistics, data for county cities. These data are collected by China's State Statistical Bureau and are downloadable (for a fee) at http://chinadataonline.org.

${ }^{41}$ Most Chinese provinces produced square input-output tables for 1997. A few of them are published in provincial statistical yearbooks. We obtained access to the final-demand columns of these matrices from the input-output division in China's National Bureau of Statistics.

${ }^{42}$ Provincial input-output tables are available for 28 provinces, as data are missing for Tibet, Hainan, and Chongqing. Four provinces (Anhui, Heilongjiang, Shandong and Guizhou) list only net outflows and are thus not useful for studying interprovincial trade. Nine provinces separate inflows and outflows into domestic and foreign sectors. Poncet (2005) deduced domestic trade flows for the other provinces using industry-level provincial import and export data from the General Administration of Customs. These data match the data reported as international trade by provinces that separate international and domestic transactions in their input-output tables. This finding gives us some confidence in the method used, as input-output tables and customs data seem to use consistent methodologies. 
This article has been cited by:

1. B. N. Fallah, M. D. Partridge, M. R. Olfert. 2010. New economic geography and US metropolitan wage inequality. Journal of Economic Geography . [CrossRef]

2. Laura Hering, Sandra Poncet. 2010. Income Per Capita Inequality in China: The Role of Economic Geography and Spatial Interactions. World Economy 33:5, 655-679. [CrossRef] 